\title{
Networking in Marketing and Advertising Companies: A Soft System Methodology Approach
}

\author{
Behrouz Zarei \\ Corporate Entrepreneurship \\ Department, \\ University of Tehran, \\ 16th St., Amirabad, Tehran, Iran \\ E-mail: bzarei@ut.ac.ir
}

\author{
Saeed Azizian \\ Information Technology \\ Department, \\ Tose Danesh Institute, \\ Mojtamae Tarbiat Moalem, \\ Sanandaj, Iran \\ E-mail: sazizian2008@yahoo.com
}

\author{
Majid Shishehgar \\ School of Industrial Engineering \\ Isfahan University of \\ Technology \\ E-mail:
}

majid.shishegar@yahoo.com.au

\author{
Setareh Sadeghi \\ Entrepreneurship Faculty, \\ University of Tehran, \\ 16th St., Amirabad, Tehran, Iran \\ E-mail: st.sadeghi@ut.ac.ir
}

\begin{abstract}
Nowadays, the quality and diversification of the services in Iranian marketing and advertising industry are growing. But, providing the customers with marketing and advertising services is still conducted using out-dated, complicated and time-consuming processes. So it seems that revising these processes is necessary. Soft system methodology (SSM) is an appropriate approach for studying complicated systems of human activities. This paper investigates the status quo of Iranian marketing and advertising industry, determines its disadvantages and defects, and proposes a new system that seems to be more efficient and effective, which brings numerous advantages to the users through changing the type of communications between the involved entities.
\end{abstract}

Keywords: Specialized networking, Marketing and advertising, Business network, Soft system methodology (SSM).

\section{Introduction}

There are some drastic changes in the marketing context, in terms of physical distance, time, markets, as well as competition, and these changes have fundamentally transformed the practice of marketing. A research group, namely "Contemporary marketing practice” (CMP), has found that managers are now more concerned with managing their marketing relationships (Lindgreen \& Antioco 2005). Over the past two decades, the approach towards marketing by the businesses across all sectors through relationships, networks, and interactions has changed. There is a great difference between such a marketing approach and the more conventional ones based on transactions influencing Four Ps, ( i.e. Price, product, promotion and place) (Lindgreen \& Antioco 2005).

It has been claimed by many researchers that we are faced with a new general paradigm shift in marketing, and the focus has changed from separate and discrete transactional exchanges to relationship management instead. Those approaches in marketing research that focus on relationships include the interaction and network approaches, which place emphasis on relationships in an industrial context (Holmlund \& Törnroos 1997). Growing globalization has affected market relationships, and they have become more spread-out geographically Nevertheless, networking in marketing has become a diagnostic tool for examining interactive systems; meanwhile one the integral parts of the network is technology (Borg 2009). The focus of newly developed networks is on relationships as well as continuous and sustainable development (Fava Neves 2007).

When the participants in a network focus on their commonly shared innovative solutions, this may lead to positive spill over. The shared standards and compatibility among partners and customers may evolve in the dynamic networks that correspond to the markets. There are two types of cooperation and collaboration networks: (1) vertical networks: established between the players of different stages in term of technology, such as suppliers and distributors, or (2) horizontal networks: competitors or suppliers of complementary products (Fava Neves 2007). The mechanisms of influencing unusual returns obtained from marketing alliance announcements by firm networks include 
increasing alliance benefits, facilitating its compliance and quality (Swaminatham \& Moorman 2009).

As a free business association, the company network can create the structures and processes not only for joint decision-making, but also for integrating the members' endeavors for designing and manufacturing goods and services, reducing the required time for entering the market or creating innovation, and creating new processes and information exchange. The opportunities for the businesses provided by the network include: interdependence among various systems and their complementary promoted by relationship investment. It should be noted that in a network, every cooperative process could have an influence on every other company in the same network.

A network can concludes of with a series of junctions, such as people or groups of companies and arches that have relationships (Trequattrini et al. 2012). The process of business networking involves management of applications unique for various conditions. It has some advantages, including providing a balance and extensive basis for relationship network, creating repeated transactions, creating a synergistic effect and achieving the results that cannot be realized by businesses separately, creating jobs and finding access to information and opportunities (Klerk \& Kroon 2008) It feels that these developments which were discussed should approve on Iranian marketing and advertising industry (hereinafter, "MKT \& Ads"). To design a business network in Iranian marketing and advertising industry by means of SSM method, this paper has been structured as follows. After this introductory section, the next section presents an explanation regarding hard and soft systems and describes SSM method. Then, our case study has been presented, which is accompanied with the research methodology and applies the SSM stages on the case under study. Finally, the paper is concluded with the Conclusion.

\section{Background}

\section{Hard vs. Soft Systems}

The study conducted by Checkland et al. (1992) places more emphasis on the distinction between 'hard' and 'soft' systems thinking (Kayaga 2008). SSM is an ever-developing methodology that has been grown into a systemic process of enquiry. It has been designed based on a comparison between real-world problem situation and conceptual models of related systems of purposeful activity (Checkland 1992). Daily events are perceived differently by the individuals participating the system. SSM allows the individuals stances and assumptions regarding the world to be brought to light, to be challenged and examined. The traditional SSM model is comprised of seven distinctive stages that can be taken as iterative or sequential processes (see Figure 1) (Por 2008). Developments in systems thinking in UK were no longer based on the biological models that had prevailed earlier systems thinking (Stowell 2009), "Hard systems thinking" is based on the idea that these systems exist and are centered on engineering a solution to an established requirement (Checkland 1981). It is supposed that the system's nature is not problematic, that the system's objectives can be defined, and that the alternative tools can be modeled and these tools can be compared using some clear and apparent criteria, which allow an appropriate selection to be made from among the most preferable forms of the system (Delbridge \& Fisher 2007). Regarding the hard systems, the problem is well structured and clearly defined, and as we already had apparent algorithms for finding the solutions. Moreover, these problems producible again.

On the other hand, Soft systems are ill-structured, have many interacting factors, have randomness and more evaluating standards. Moreover, we must frequently think about human intervention into systems. These problems are almost unique (Pesl and Hrebicek 2003). Hard systems problems have clearly-defined desirable objectives (e.g., to manufacture a motor vehicle) and are characterized by these objectives (Nidumolu et al. 2006). Checkland and Scholes (1990a) maintain that conflicts in technology and organization are not of technical per se, but are related to human factors (Saad et al. 2006).

The so-called 'hard methodologies' (such as operational research) are directed towards structured issues and objectives, while 'soft issues' of social systems, most of the time, present unclear and poorly established objectives (Ferrari et al. 2002). While the soft systems (problems) have the goals that, they may be both ambiguous and unrelated, if they can ever be identified, hard systems may give rise to a project with clearly defined objectives and deliverables and a defined project completion deadline (Nidumolu et al. 2006). 


\section{Soft System Methodology}

SSM was first established by Peter Checkland and his colleagues at Lancaster University and was used as a method for studying systems with certain features and high intervention by human factors. One of the first cases in which this system was employed was health care system, and this was done by Checkland himself.

Scientists and engineers have frequently been trained on the principle of reductionism, because analysis of a problem focuses on its structure and decomposition that shows how things work. This process centres on decomposition, explanation and synthesis of the problems (Warwick 2008). SSM is a tool for modeling, learning and meaning development (Williams 2005). It is an empowering approach for participants for finding their ways to agree upon the action which they think will 'improve' the problem situation (Checkland \& Winter 2006). This vision will lead to the evolutionary process of analysing the flow of information, definition of databases, encoding knowledge and finding the requirements of online observation (Sørensen et al. 2010). SSM approach clearly presupposes that different people and groups have different worldviews, which concern them as human activity systems (HASs) consisted of a set of interrelated activities in a logical structure which make a purposeful whole (Tajino et al. 2005).

There are four types of activities, which form the learning cycle, i.e. SSM:

1. Understanding a problematic situation

2. Selecting determined models of activities

3. Finding more information about the situation

4. Defining the actions, which make the situation better (Delbridge 2008).

HAS is defined as a collection of activities in which people are employed and the relationship between those activities are established purposefully (Platt and Warwick 1995). SSM process is illustrated in Figure 1; it does not involve a concrete process to be followed (Tajino et al. 2005). The methodology creates a way through which the complexity of the humans' interactions can be examined, described and made sense of (Warwick 2008).

Stages 1 and 2: These two stages are reported together, since both of them are parts of the process of explanation by which we search for the richest would-be "panorama," not of the problem, but of the real situation in which the problem is arisen. This expression should be done to minimize the effect of understood structures, taking into account that stages 1 and 2 will be integrated with the "real-world" context (Ferrari et al. 2002).The first stage, in the real world, is to accept, investigate and define the situation in one way or another. Here, we are not defining the problem but assessing the general area that favors us (Williams 2005). At this stage, the collected data gives an informal picture of the issue (Checkland \& Scholes 1990b), while, in the next stage, we provide a rich picture of the status quo, which is a flexible graphical technique representing the situation, problem or concept (Horan 2000). The situation of the problem is expressed by means of the rich picture provided in stage 2 . The rich pictures are diagrammatic illustrations of entities, structures, processes, relationships and issues of the given situation (Por 2008). There is no established technique or typical form to present the rich picture, i.e. it is usually shown as an ordnance survey map, mind map, and etc (Nagi et al. 2012).

Stage 3: The third stage of the methodology involves describing the suitable and related systems. These systems have been introduced as the central definition (Checkland \& Scholes 1990b). At this stage, the methodology moves to the field of systemic thought, applying the concepts of an outstanding system to describe how the system is (Ferrari et al. 2002). At this stage, basic definitions are compiled by assembling CATWOE elements, as described in Table 1.

Table 1: Elements of CATWOE and their definition (Source: Mingers, Liu \& Meng 2009)

C Customer: direct beneficiary or victim of the system's output

A Actors who carry out the activities of the system

T Transformation that produces the output as a transformed version of the input

W Weltanschauung / worldview that makes the activities of the system meaningful

O Owner of the system. a wider system that can create or destroy it

E Environment of the system, especially constraints given that the system must accept

CATWOE is usually used to enrich both the "Root Definition" and the "Conceptual Model", but it can also 
be looked at as a method for assessing the perfectness of such definitions and models (Bergvall-Kareborn et al. 2004). CATWOE shows a mechanism or checklist for examining the principal definitions and ensuring that the selected terms are as clear as possible and that they represent the best choice for the meaning they take on

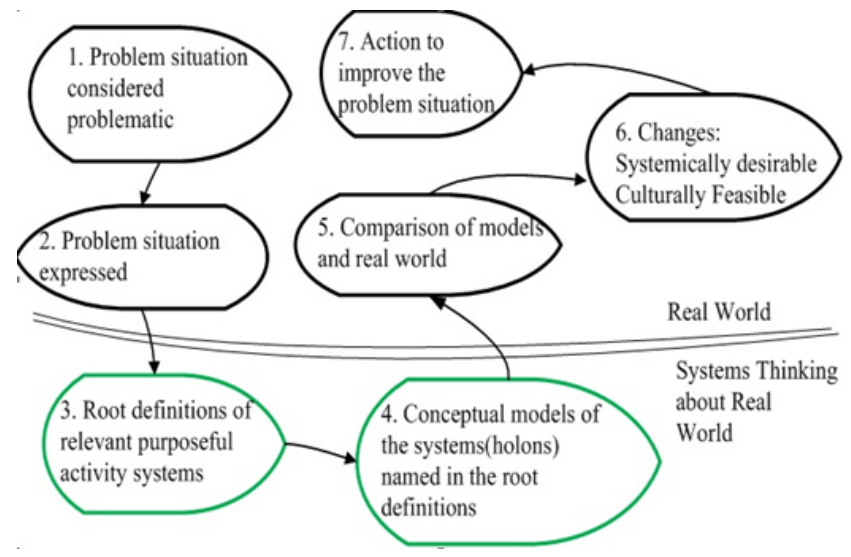

Fig. 1. The conventional seven-stage model of SSM (Source: Checkland \& Scholes 1990)

(Nagi et al. 2012). There are six elements, which constitute a well-formulated root definition making use of the mnemonic CATWOE (Por 2008). Root definition is normally thought of as a restricted explanation of what systems have to do, who is going to perform it and who is in charge of doing it (Por 2008). Root definition can be presented as 'a system to do $X$ by means of $Y$ in order to achieve $\mathrm{Z}$ ', where $\mathrm{Y}$ and $\mathrm{Z}$ are related to the owners' long-term objectives, and there must be an arguable connection, which makes $\mathrm{Y}$, an appropriate means for doing X (Checkland \& Scholes 1990b).

It should be explained that in both CATWOE and the root definition, we have an overview of the ideal situation. This overview within the elements of CATWOE and the root definition is expressed too generally. Some more details about the ideal situation are presented in stage 4 and also in the Conceptual Model.

Stage 4: SSM makes a clear distinction between the messy and complex bit of the 'real world,' which is the subject of some forms of investigation, and a reference (conceptual) model, which is used to structure the investigation (Wilson \& Haperen 2009). Stage 4 is intended for creating a conceptual model, which allows us to reach the transformation explained in stage 3. Still in the systemic field, this stage makes use of systems' concepts to describe how the outstanding systems should be for the given context. Such description can be done at different levels of detail, through making use of the hierarchical concept of the systems. After having created the conceptual models, they should be validated through comparison with a formal system and/or with other systemic conceptions. A formal system has the following components:

1. Purpose/assignment

2. Performance assessment

3. Process of decision-making

4. Interrelated subsystems

5. Interaction with the periphery

6. Physical and human resources

7. Continuity (Ferrari et al. 2002).

The conceptual model identifies which activities need to be contained in those special HASs. This model is not concerned with how these activities will be performed; instead, it will be compared with the real world to highlight possible changes in the real world. All elements of CATWOE must be included somewhere in this model; otherwise, it will be incomplete (Platt \& Warwick 1995).

Stage 5: Stage 5 is the stage that refers back to the real world. At this stage, the conceptual model, which is created at Stage 4, will been compared with the real world expressed at Stage 2 (Por 2008). The most common method for this purpose is to create a matrix that considers each part and asks: 'Does this process have any profits?'

Stage 6: Having referred to the real world again, stages 6 and 7 are analysed together. In these stages, based on the comparisons from stage 5 , changes in the processes, structures, and viewpoints are suggested (Ferrari et al. 2002). Stage 6 is used to identify the various possible changes in terms of desirability and possibility (Por 2008). The conceptual model will be compared with the real world to make prominent the possible changes in it. These modifications may be those activities in the conceptual model, which do not exist in the real world (Platt and Warwick 1995).

Stage 7: Stage 7 is the last stage in which the most favorable and possible changes distinguished at Stage 6 are practiced (Por 2008). Here, recommendations for change will be given. It is important to understand that when these changes have been done, the problem situation will be modified (Platt \& Warwick 1995). The 
last stage completes the process and may begin a new procedure (Williams 2005).

In this paper, we investigate the current and the ideal situations in Iranian MKT \& Ads industry. Therefore, we present the whole status quo in one sheet by providing a comprehensive rich picture including all actors, their roles and the relationships between them. From third stage to seventh, we define and design the ideal situation, generally and develop this design. Finally, we finish the paper by discussion and conclusion.

\section{Case Study}

There is a growing trend in quality and diversification of the services in Iranian MKT \& Ads industry. However, providing the customers with such services is still conducted using outdated, complicated and time-consuming processes. Nevertheless, there are thousands of MKT \& Ads companies; about 90 percent of advertising market share is owned by only 10 percent of the leading companies and there is an intense competition.

There are only 259 newly issued licences for advertising agencies and 389 ones also have been extended by Informatics and Advertisement Office, Ministry of Culture and Islamic Guidance; meanwhile, the highest number of issued and extended licences belong to Tehran province followed by Isfahan, Khuzestan, Fars and North Khorasan Provinces. According to IA office, there are currently 6604 active advertising agencies in 32 provinces of Iran, 1949 of them are based in Tehran. As presented in Table 2, according to the IA office, the advertising expenses by 10 superior companies on TV, newspapers and magazines have been totally \$27,155,200 in Jan 2012.

Table 2: Advertising expenses in Jan, 2012

\begin{tabular}{cccc}
\hline Companies & TV (USD) & $\begin{array}{c}\text { Newspaper } \\
\text { (USD) }\end{array}$ & $\begin{array}{c}\text { Magazine } \\
\text { (USD) }\end{array}$ \\
\hline $\begin{array}{c}\text { 10 superior } \\
\text { companies } \\
\text { Other }\end{array}$ & $16,255,600$ & $2,279,200$ & 337,200 \\
companies & $7,662,400$ & 625,600 & 282,400 \\
\hline
\end{tabular}

Refrence : http://www.ad.gov.ir/research/19

\section{Stage 1 and 2: The Definition of the Situation}

In these stages, in order to describe the processes of information exchanges and demand for receiving MKT \& Ads services, special symbols and cycles have been used. In SSM method, there is no limitation for the types of presentation. Researchers are free to use any preferable ways to express their opinions and viewpoints. Figure 2 shows these processes. Our aim is to investigate the status quo of MKT \& Ads industry and the processes and information exchange between the involved actors and entities that can be divided into 6 groups:

1. Customers: individuals and companies who demand MKT \& Ads services from MKT \& Ads companies.

2. Marketing companies: the individuals and companies who supply marketing services like marketing consultation, marketing strategies, marketing and market planning, market research, competitors' and market situation monitoring, etc.

3. Advertising companies: advertising agencies and companies that supply advertising services. Advertising has various types and extended ranges. In our definition, advertisers include designers and executors.

4. The sextet organizations: there are six main organizations, namely Islamic Republic of Iran Broadcasting, Municipality of Tehran and Organization of Tehran Beautification, newspaper \& magazine offices, Bus-driving organization, Taxi-driving organization, and Subway media, each with urban and provincial centres. As advertising plans administrator, they all play a basic role in execution of advertising.

5. Government: Ministry of Culture and Islamic Guidance as a governmental organization is responsible for issuing advertising licences, supervising advertisements to comply with Islamic rules and executing methods of advertising plans.

6. Audiences: the people who are exposed to advertising products and services and the 
main target of advertising production. These are consumers and potential buyers and customers (MKT \& Ads consumers) for goods and services.

MKT \& Ads consumers, who are referred to as "customers" in this paper, contact the advertising companies in order to get them advertise their goods or services, after their companies' marketing consultant recommendations or after receiving consultation from marketing companies. So they look for suitable companies that can perform this in some ways: (1) they may directly know someone in their communication network; (2) someone can be introduced by their relatives, friends, colleagues and employers; (3) they may meet someone through their advertising; (4) they hold bidding process for their advertising demands and select someone or a company due to the lower price or upper quality etc., this method is adopted only by bigger companies. Obviously, they are more sensitive to the quality, tariff, honesty etc. in the second and third methods. Sometimes, their marketing consultation companies may offer some advertising companies instead of receiving a commission from marketing companies for such preferences. Subsequently, the advertising companies will compile advertising campaigns for them and will get help from marketing companies if needed, which happens rarely; then after confirmation of the campaigns by the customers, the campaigns will be executed.

In this step, customers may look for suitable advertising companies by themselves or may assign all of such duties to that advertising company that has compiled the advertising campaigns, and advertising company will become the customers' advertising consultant. Advertising companies perform those parts of the works they are experienced at and assign other parts to other companies, as a result:

(1) The advertising company finds the suitable companies, negotiates with them, determines the terms and conditions, and finally the customer concludes a contract with them and the advertising company will be responsible of all duties as the advertising consultant, it has its own revenue and in addition, will be given a commission from the referred companies to customer (this is common especially for renting billboards from companies possessing them).

(2) The advertising company only introduces the suitable companies and gets its commission from them, and the customers will be responsible of all issues related to their purchase.

(3) The advertising company directly concludes contracts with suitable companies and earns profit through receiving more money from customer or paying less money to the advertising company.

Moreover, performing advertising depends on its type, and often depends on related organization such as Islamic Republic of Iran Broadcasting (IRIB), municipalities, newspapers, etc, or requires cooperation among several advertising companies. What happen in this inefficient system is that advertising companies, in order to win in the competitive market, pay a portion of the charged fees gained from the sextet organizations such as Islamic Republic of Iran Broadcasting or newspaper - to the customers to steal the job from their colleagues. Therefore, the criterion for selection of the companies is paying back more commission rather than their services quality. This means that advertising agencies and companies not only cannot earn suitable income from the customers for creating teaser, but also they have to pay some portion of their commission received from Islamic Republic of Iran Broadcasting.

Likewise, the status quo lacks enough efficiency and effectiveness to deliver good quality, on-time and effective MKT \& Ads services. The communications among entities are discrete and there is no centralization for information exchange among the entities and no room for evaluating the activities of the companies and creating free and positive competition. The whole of the process, from finding suitable advertising and marketing companies, to execution of advertising campaigns and increasing sales is traditional, time-consuming and is accompanied by high risks. In addition, the lack of companies' integrated cooperation with each other leads to wasting a lot of time, energy and resources for companies and creates opportunities for abusive behaviour by scant companies who can earn huge profits in this process and are not committed to transparency of information. Consequently, a massive number of MKT \& Ads with better and more effective services cannot obtain high class and expensive advertising market share. In such situation, MKT \& Ads industry will not develop and grow up sufficiently. Moreover, most of such activities require physical presence and communications in real world.

Figure 2 presents a comprehensive description of the status quo of processes and information exchange 
between users, companies, audiences and other involved entities. The aim of presenting this rich picture is to clarify information cycle and relationships between involved entities in MKT \& Ads industry from the start point to the end of supplying services.

\section{Stage 3: Root Definition}

Root definition: The specialized network of Iranian MKT \& Ads companies is a system that can receive, collect, store, classify and organize MKT \& Ads information from various resources and then present them for users in an integrated manner. The system will change the method of information and communication exchange between components using new technologies in comparison with the old one. Table 3 present the definition of CATWOE's elements in the proposed system.

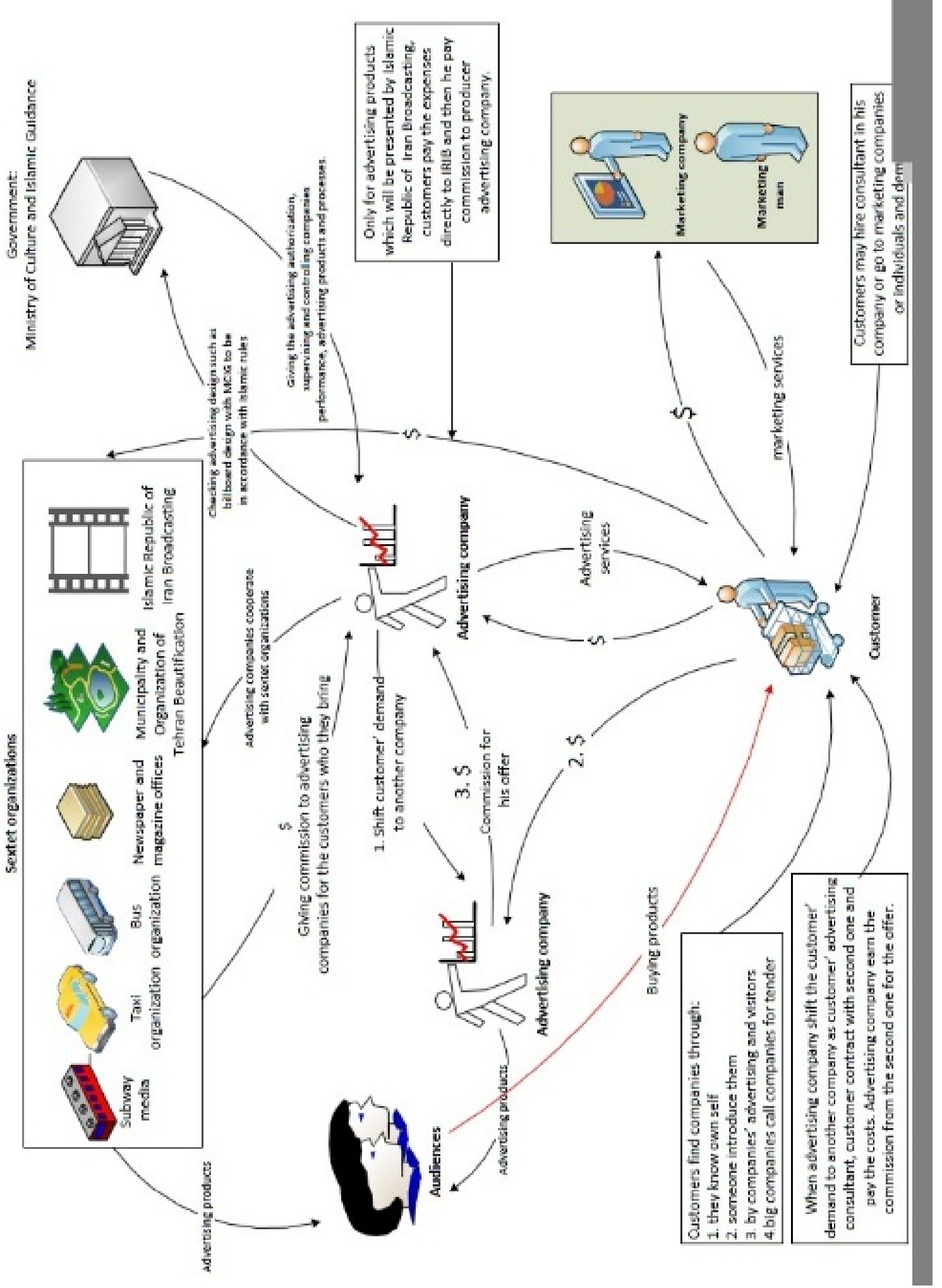

Fig. 2. The rich picture of the current situation of the MKT \& Ads industry (source: developed for this study) 
Table 3: The basic elements of CATWOE in the proposed system (source: developed for this study)

\begin{tabular}{|c|c|}
\hline Elements & Definition \\
\hline Customers (C) & $\begin{array}{l}\text { Marketing companies, advertising } \\
\text { companies, customers. }\end{array}$ \\
\hline Actors (A) & $\begin{array}{l}\text { The sextet organizations, } \\
\text { government and any related } \\
\text { influential organization, Marketing } \\
\text { companies, advertising companies, } \\
\text { customers }\end{array}$ \\
\hline $\begin{array}{l}\text { Transformation } \\
\text { process }(\mathrm{T})\end{array}$ & $\begin{array}{l}\text { As the centralized reference } \\
\text { centre, receives unorganized and } \\
\text { diffuse MKT \& Ads information } \\
\text { from various information } \\
\text { resources, processes and makes } \\
\text { the balance between them and } \\
\text { presents the organized and } \\
\text { coherent information to users. }\end{array}$ \\
\hline $\begin{array}{l}\text { Weltanschauung } \\
\text { (W) }\end{array}$ & $\begin{array}{l}\text { The best information flow } \\
\text { between different entities and } \\
\text { users in a conjunct manner is done } \\
\text { by this system that causes } \\
\text { decreased costs, increased quality, } \\
\text { saving time and energy, } \\
\text { improvement of system structure } \\
\text { and processes and creating free } \\
\text { and positive competition. }\end{array}$ \\
\hline Owner (O) & $\begin{array}{l}\text { Everyone who provides the prime } \\
\text { investment of the system including } \\
\text { the companies or individuals }\end{array}$ \\
\hline $\begin{array}{l}\text { Environmental } \\
\text { constraint (E) }\end{array}$ & $\begin{array}{l}\text { The most important environmental } \\
\text { constraints are out-dated and } \\
\text { traditional existing system, users' } \\
\text { habits and profits due to } \\
\text { unorganized structure and } \\
\text { processes, lack of interest and } \\
\text { desire to change and use of new } \\
\text { systems and technologies, } \\
\text { complicated and difficult structure } \\
\text { of MKT \& Ads industry in Iran. }\end{array}$ \\
\hline
\end{tabular}

\section{Stage 4: Developing the model}

In ideal situation, the network makes a good data flow among involved entities. MKT \& Ads companies announce their accurate and detailed information such as their $\mathrm{CV}$, working fields, working samples, customers, contact etc. and also their fields of expertise and interest. Customers - MKT \& Ads consumers declare the accurate information of their demands and needs and also the attributes and criteria of their desirable MKT \& Ads companies, too. Here, the network plays the role of information exchange, and connects the best MKT \& Ads companies and customers to each other. For wider services that several companies are needed, the system offers a small network of companies to the customer. Moreover, customers can find their desirable companies by searching based on defined criteria such as location, type of services, working field, the class of people the services are presented to, price etc. and can contact them. In addition, the companies who tend to cooperate with other companies that are related to or support their needed services are suggested by the specialized network to each other and can create a small network between them. Therefore, the customers can look for the networks and groups of MKT \& Ads companies that cover all MKT \& Ads needs and demands by themselves rather than search for each of them. In addition, all tenders and bidding processes (for example for billboards of the municipality and Organization of Tehran Beautification) can be conducted online without physical presence in the system.

In ideal situation, the sextet organizations and Ministry of Culture and Islamic Guidance or other key organizations will login to the proposed system and perform information and financial exchange with MKT \& Ads companies through the network. In addition, audiences of advertising goods and services including the public may enter into information cycle by commenting about advertising products such as teasers, packaging of customers' goods and services, etc. and can play an important role in ranking of MKT \& Ads companies involved in the process of creating and execution of advertising services. Their feedback, therefore, will be helpful both for the customers and for market research and monitoring companies. Purchasing by the audience will complete the cycle and compensate customers' expenses.

The various subsystems of the proposed system defined based on legal, structural, technological and financial requirements are listed in Table 4.

Figure 3 depicts the conceptual model of the proposed system and shows the activities required for achieving the desirable system in four phases.

The first phase is devoted to performing studies and preliminary design of the system including software, hardware, processes, structures and etc. and also the 
Table 4: Subsystems and the relevant tasks in the proposed system (source: developed for this study)

\begin{tabular}{l}
\hline Subsystem \\
\hline $\begin{array}{l}\text { Receiving } \\
\text { information }\end{array}$ \\
\\
Processing and \\
classifying \\
information
\end{tabular}

\section{Sending} information

\section{Cooperation} suggestion

\section{International cooperation suggestion}

\section{Rating by audiences}

Ranking of
users

Storing information

Reporting

Marketing

\section{Activity}

This subsystem receives and collects the information from different sources such as MKT \& Ads companies, customers and other involved entities in the processes.

The subsystem processes and classifies received information related to demand and supply of MKT \& Ads services, based on various criteria like location, work field, experience, price etc. and presents them for certain users.

This subsystem sends out the requested information in various types according to the demands of users.

This subsystem suggests the best choice of MKT \& Ads companies and customers to each other and also the most suitable partner companies to each other based on their defined criteria.

This subsystem broadens the cooperation boundaries by connecting the customers and MKT \& Ads companies to international ones.

This subsystem makes commenting possible about advertising products and also the rating of the advertising companies.

The MKT \& Ads companies will be ranked based on their past records, experiences, financial turnover by this subsystem and also with the help from rankings by the audience.

Users' data including the information entered by themselves and their records, reports etc. will be stored in the system safely. It should be mentioned that revealing and making the information public can be done with only specific permission.

Statistical reports of the performed activities and operations of the system, users and any other performance of the system at different times.

This subsystem supports the marketing activities such as sending

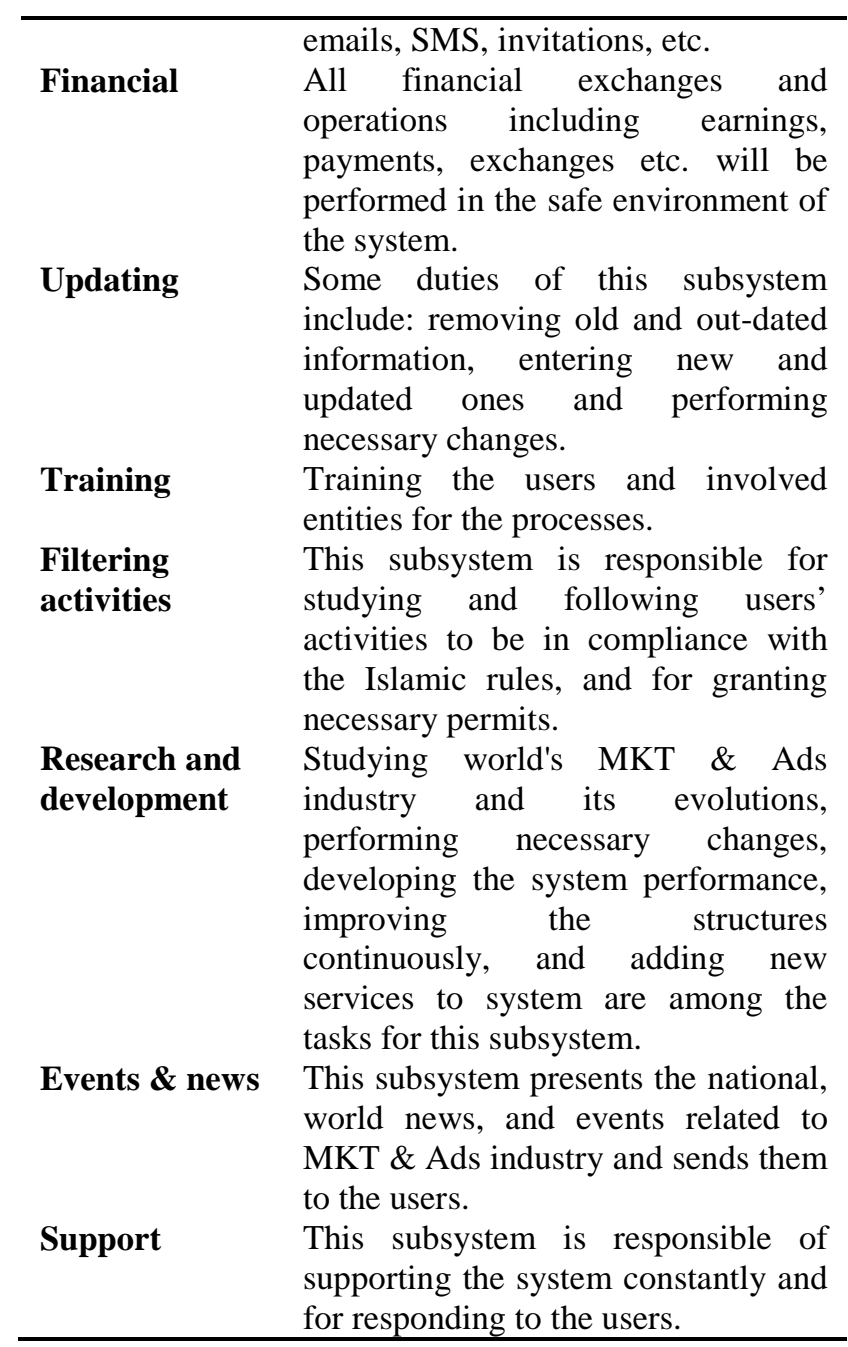

initial planning for marketing and attracting users. In the second phase, the prototype of the system will be implemented in a monitored and limited scale and attracting the users will take place, which include customers and MKT \& Ads companies in order for testing the pilot system and understating its deficiencies. Based on the identified defects and second phase's feedbacks, the system will be improved or changed in the third phase. In the fourth phase, the required activities will be done in order for developing and promoting system services to provide users' needs and updating the system and its compliance with the environment.

The ideal systems model is the result of studying sources of information, relevant documents, and interviews with companies' managers, practitioners and beneficiaries of the information cycle of MKT \& Ads services as well as the professionals and experienced 
experts in marketing. It also requires holding information systems and network training courses and conducting debates and polls regarding both the current and ideal situations, and also problems of the existing system and their unsatisfied needs and issues. Moreover, studying the information sources related to SSM theory and the case studies conducted using this theory will broaden our horizons and provide good inspiration, especially for the four-phase conceptual model.

Since the SSM does not specify any limitation in expressing opinions, we have shown our proposed model in figure 3 and 4 , which indicate to our viewpoints. Figure 3 presents the formation of a desirable system and its requirements in 4 phases. Figure 4 shows the working process of a desirable system in a general design in which MKT \& Ads companies and customers are connected with each other and also with the network and can exchange their information. Advertising companies can easily do their financial and information exchange with the sextet organizations through the network. MKT \& Ads companies provide a comprehensive and complete continuum of MKT \& Ads services required by their customers by creating a small network with each other. Such specialized network connects the most appropriate continuum of supplying services to the most appropriate customers according to the received information. The role of the audience has been also considered in terms of giving feedback to the customers and MKT \& Ads companies regarding the provided MKT \& Ads services.

"Insert Figure 3 about here"

"Insert Figure 4 about here"

\section{Stages 5-7:}

At this step, a comparison between the real world and the ideal model will be conducted and some ideas for the development of system will be proposed. Table 5 presents this comparison.

“Insert Table 5 about here”

\section{Conclusion \\ - Summary of the research}

The MKT \& Ads industry is traditional, inefficient and slowly-growing in many developing countries. However, it plays a vital role in the growth and survival of businesses, and thereby increases the country's development and national manufacturing. This paper, through designing a specialized network of MKT \& Ads companies using SSM method, tries to facilitate the realization of this objective by improving the process of providing MKT \& Ads services, from the customers' demands to the companies' supply.

Information technologies have made numerous progresses (Ghapanchi et al. 2012a), (Ghapanchi et al. 2012b), (Khakbaz et al. 2010), (Ghapanchi and Aurum 2011). Several research have been conducted on various areas of technology (Ghapanchi et al. 2012a), (Ghapanchi et al. 2012b), (Ghapanchi et al. 2008), (Ghapanchi et al. 2011), (Ghapanchi et al. 2012c), (Merati et al. 2010) including networked marketing.

After a brief survey of the literature and SSM, we investigated different dimensions of Iranian MKT \& Ads industry and expressed the status quo and its problems. Then, the desirable model of the system was designed, explained and compared with the current situation. In order to confirm that this network is practical and usable, some interviews were performed with MKT \& Ads companies' managers, experts, beneficiaries and entities involved in the current system. All of them confirmed the proposed system's effectiveness and performance.

- Summary of key findings of the research

Some of the important features of this paper include:

1. Studying the structures and processes and relationships between the components involved in the process of presenting MKT \& Ads services to the customers.

2. Defining the status quo including entities, their relationships and existing problems by means of SSM language.

3. Presenting effective strategies for solving problems and determining the new improved structures, processes and relations for the best information flow among components involved in the processes.

4. Designing a specialized network as a new and desirable system with the capabilities including centralization of information and financial exchanges between involved entities, creating some small networks between MKT \& Ads companies among each other to integrate customers' needed services, 
and inclusion of the audiences in the system as an important element for providing feedback to

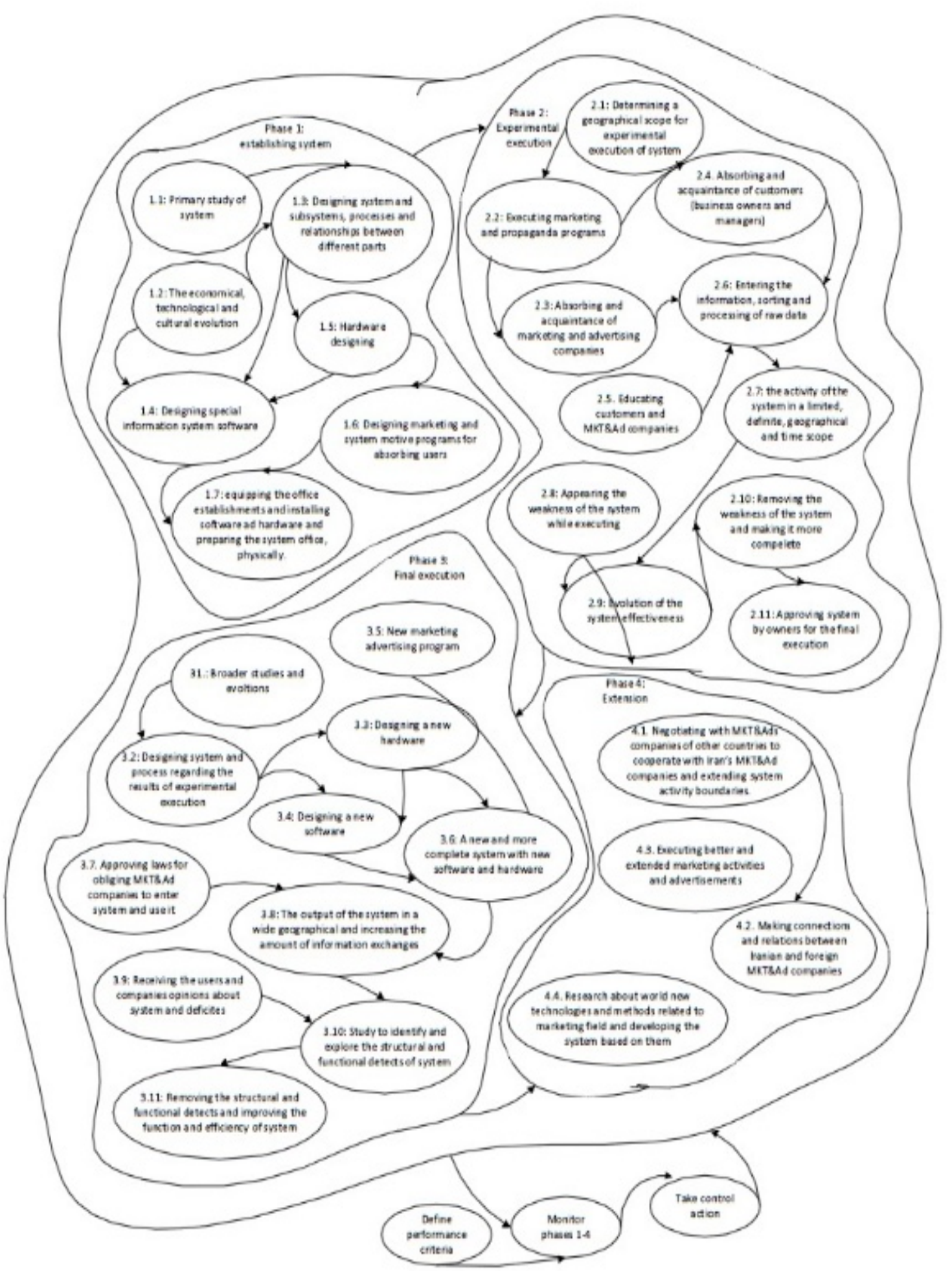

Figure 3: The Conceptual model of the specialized network of MKT \& Ads companies (source: developed for this study) 


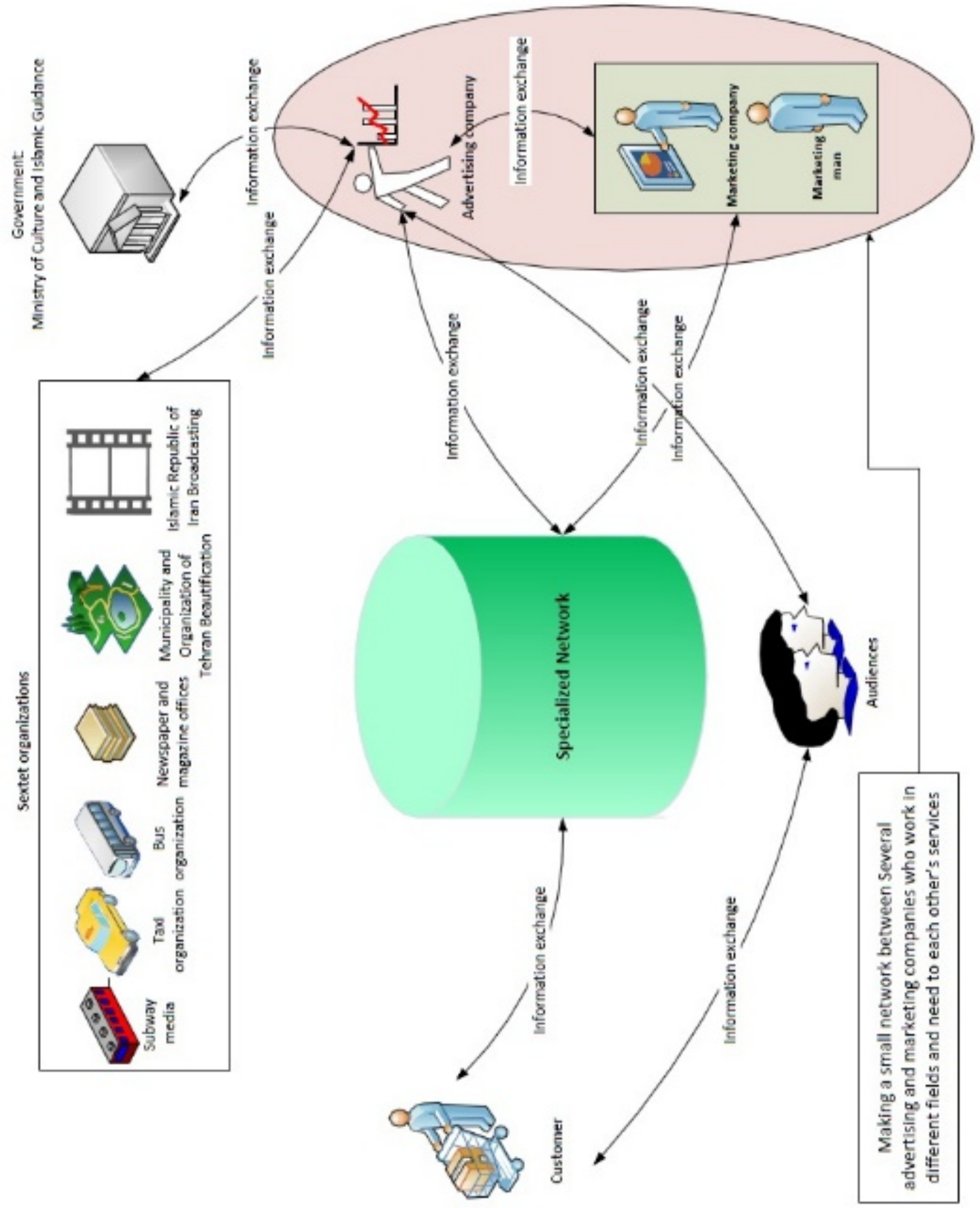

Figure 4: The sophisticated design of information cycle of the proposed system 
Table 5: Evaluating various aspects of the conceptual model (Source: developed for this study)

\begin{tabular}{|c|c|c|c|c|c|}
\hline & $\begin{array}{l}\text { A centex to } \\
\text { send and } \\
\text { receive } \\
\text { information } \\
\text { related to } \\
\text { MKT \& Ads } \\
\text { services of all } \\
\text { users }\end{array}$ & $\begin{array}{l}\text { Direct and } \\
\text { convenient } \\
\text { connection } \\
\text { with other sections } \\
\text { and entities }\end{array}$ & $\begin{array}{l}\text { The } \\
\text { possibility of } \\
\text { providing } \\
\text { a network and } \\
\text { continuous services } \\
\text { from several } \\
\text { companies }\end{array}$ & $\begin{array}{l}\text { The use of new } \\
\text { technologies in } \\
\text { MKT \& Ads } \\
\text { industry }\end{array}$ & $\begin{array}{l}\text { The relationship } \\
\text { between audiences, } \\
\text { MKT \& Ads } \\
\text { companies } \\
\text { and customers and } \\
\text { receiving feedback }\end{array}$ \\
\hline $\begin{array}{l}\text { Does it exist } \\
\text { in the real } \\
\text { world? }\end{array}$ & Not available & Not available & Not available & Not available & Not available \\
\hline $\begin{array}{l}\text { How does it } \\
\text { behave? }\end{array}$ & $\begin{array}{l}\text { All users } \\
\text { tranafer their } \\
\text { MIKT \& Ads } \\
\text { services } \\
\text { demand and } \\
\text { supply by } \\
\text { referring to the } \\
\text { specialized } \\
\text { networks. }\end{array}$ & $\begin{array}{l}\text { Inatead of time- } \\
\text { consuming and } \\
\text { costly physical and } \\
\text { verbal } \\
\text { communications, } \\
\text { financial and } \\
\text { information } \\
\text { exchange takes place } \\
\text { in its area. }\end{array}$ & $\begin{array}{l}\text { In the system, some } \\
\text { companies who work } \\
\text { in the different fields } \\
\text { of MKT \& Ads make } \\
\text { a small network, and } \\
\text { provide the } \\
\text { customers' needs in } \\
\text { an integrated manner } \\
\text { without referring the } \\
\text { customers to the } \\
\text { other companies. }\end{array}$ & $\begin{array}{l}\text { Communications, } \\
\text { relationships and } \\
\text { processes change } \\
\text { in a digital and } \\
\text { systematic form }\end{array}$ & $\begin{array}{l}\text { The audiences inside } \\
\text { system provide their } \\
\text { comments, } \\
\text { experiences and } \\
\text { suggestions } \\
\text { regarding the } \\
\text { delivered advertiaing } \\
\text { products and gervices } \\
\text { to MKT \& Ads } \\
\text { companies and } \\
\text { customers. }\end{array}$ \\
\hline $\begin{array}{l}\text { How its } \\
\text { performance } \\
\text { is identified } \\
\text { and } \\
\text { measured? }\end{array}$ & $\begin{array}{l}\text { Solidarity and } \\
\text { integration of } \\
\text { processes, } \\
\text { increasing the } \\
\text { system } \\
\text { effectiveness, } \\
\text { and using the } \\
\text { exchanged } \\
\text { information as } \\
\text { an indication of } \\
\text { the excellence } \\
\text { and organized } \\
\text { performance of } \\
\text { this syatem } \\
\text { rather than the } \\
\text { old one. }\end{array}$ & $\begin{array}{l}\text { Expenses reduction, } \\
\text { ease of } \\
\text { communication, } \\
\text { quality enhancement } \\
\text { and interface } \\
\text { effectiveness } \\
\text { demonstrate that this } \\
\text { system is better than } \\
\text { the old one. }\end{array}$ & $\begin{array}{l}\text { Increasing, } \\
\text { customers' } \\
\text { gatisfaction and } \\
\text { quality of presenting } \\
\text { gervices to them, } \\
\text { more advertiging } \\
\text { effectiveness on the } \\
\text { audiences will be the } \\
\text { result of the } \\
\text { companies' } \\
\text { cooperation in a } \\
\text { systematic and } \\
\text { integrated manner. }\end{array}$ & $\begin{array}{l}\text { Ease of } \\
\text { communication } \\
\text { and financial and } \\
\text { informational } \\
\text { exchange, } \\
\text { simplification of } \\
\text { processes and as a } \\
\text { result, users' } \\
\text { gatisfaction, leads } \\
\text { to the superiority } \\
\text { of the new system } \\
\text { againat the old one. }\end{array}$ & $\begin{array}{l}\text { MKT \& Ads } \\
\text { companies' } \\
\text { awareness of the } \\
\text { points of views of the } \\
\text { audience regarding } \\
\text { their gervices has a } \\
\text { positive impact for } \\
\text { improving their } \\
\text { performance, } \\
\text { reinforcing their } \\
\text { strengths and } \\
\text { eliminating their } \\
\text { wealnesses. } \\
\text { Moreover, customers } \\
\text { will know about the } \\
\text { effectiveness of their } \\
\text { costs. }\end{array}$ \\
\hline $\begin{array}{l}\text { Is this } \\
\text { process any } \\
\text { good? }\end{array}$ & $\begin{array}{l}\text { Yes, it is. } \\
\text { Because it } \\
\text { causes } \\
\text { reduction in } \\
\text { measy and } \\
\text { crowded } \\
\text { information } \\
\text { exchange, } \\
\text { cheating and } \\
\text { incompetency, } \\
\text { and provides } \\
\text { tranaparency } \\
\text { and ease of }\end{array}$ & $\begin{array}{l}\text { Yes, because it leads } \\
\text { to comfort of users } \\
\text { and involved entities, } \\
\text { it is timesaving, and } \\
\text { energy-saving, and } \\
\text { also increased the } \\
\text { relationship with } \\
\text { other provinces and } \\
\text { countries and bring } \\
\text { more profit. }\end{array}$ & $\begin{array}{l}\text { Yes, because of the } \\
\text { integrated services of } \\
\text { the companies, their } \\
\text { awareness of working } \\
\text { manner of each other, } \\
\text { convergent } \\
\text { viewpoints and } \\
\text { sharing of resources, } \\
\text { an incredible } \\
\text { increasing in quality, } \\
\text { effectiveness and } \\
\text { efficiency of MKT \& } \\
\text { Ads gervices and }\end{array}$ & $\begin{array}{l}\text { Yes, it provides } \\
\text { convenience and } \\
\text { increased } \\
\text { communication } \\
\text { and income, } \\
\text { reduced expenges } \\
\text { and time. }\end{array}$ & $\begin{array}{l}\text { Yes, it provides } \\
\text { feedback for } \\
\text { advertising } \\
\text { companies, so an } \\
\text { improvement in the } \\
\text { quality of furture } \\
\text { services, better } \\
\text { ranking of the MKT } \\
\text { \& Ads companies, } \\
\text { and better choices for } \\
\text { customers in future } \\
\text { will become } \\
\text { possible. }\end{array}$ \\
\hline
\end{tabular}


probable problems and obstacles that lies ahead, such as training users to enter and use the system according to their knowledge and skills levels.

This creates a win-win relationship for all components of the system. Customers will achieve extensive sources of independent and networked MKT \& Ads companies by spending less money or even free of charge. MKT \& Ads companies will save their cost and resources and also a greater number of customers from international businesses can be attracted and more profits can be made. Additionally, access to other partners and the sextet organizations will become easier.

Government and the sextet organizations can monitor the performance of the companies more easily and more accurately, and can communicate with them. Such a system will reduce or eliminate the illegal benefits of some components that make use of such conditions for their own advantages and prevent the customers from finding competent and creative companies.

It is necessary to mention that we only conducted our studies and research from a systematic and management viewpoint and using the soft method. Implementing such a system in current situation requires the willingness and cooperation of the components, or at least the most important ones. Making the information flow possible among the entities requires the willingness of all of them. Surely, it takes a considerable time for: introducing a new system to the components, justifying its features and benefits, providing trainings required for working with such system, making necessary arrangements among key organizations and governmental organs and promoting the culture for using new and high-tech systems, instead of the outdated and traditional ones.

\section{- $\quad$ Practical limitations}

One of the probable environmental constraints that may lie ahead is that both large and powerful beneficiaries and also small companies refuse to accept this system. The former, which includes MKT \& Ads companies and customers, may refuse because of the profit they can get from the market mess, while the latter may not accept because of their fear of getting lost between powerful companies. Other constraints include the difficulty of accepting the new system by governmental organs and the sextet organizations, restrictions imposed on internet use and the threat of disclosure of the confidential business information of the companies.

\section{- $\quad$ Limitations and future directions}

Some suggestions that can be the basis for future researches include:

- The legal status of such systems in comparison with the traditional ones

- $\quad$ Studying and designing a business model of this ebusiness proposal

- Studying and researching the approaches for adopting appropriate and effective MKT \& Ads methods for such a system to attract the MKT \& Ads companies.

The implementation of the specialized network of MKT \& Ads companies may be faced with difficulties and obstacles, and this can be a new subject for future researches.

\section{References}

1. Ghapanchi, A.H. and Aurum, A. and Daneshgar, F. (2012a). "The Impact of Process Effectiveness on User Interest in Contributing to the Project," Journal of software, 7 (1), 212 -219.

2. Ghapanchi, A.H. and Tavana, M. and Khakbaz, M.H. and Low, G. (2012b). "A Methodology for Selecting Portfolios of IS/IT Projects with Interactions and Under Uncertainty," International Journal of Project Management, 30 (7), 791-803.

3. Ghapanchi, A.H. and Aurum, A. (2011). "Measuring the Effectiveness of the Defect-Fixing Process in Open Source Software Projects," 44th Hawaii International Conference on System Sciences (HICCS), 4-7 January 2011, Hawaii, US.

4. Ghapanchi, A.H. and Khakbaz, M.H. and Jafarzadeh, M.H. (2008). "An Application of Data Envelopment Analysis (DEA) for ERP System Selection: Case of a Petrochemical Company," International conference of information systems (ICIS), December 2008, France, Paris.

5. Ghapanchi, A.H. and Aurum, A. and Low, G. (2011). "Creating a Measurement Taxonomy for the Success of Open Source Software Projects, " First Monday, 16(8)

6. Ghapanchi, A.H. and Aurum, A. and Daneshgar, F. (2012c). "The Impact of Process Effectiveness on User Interest in Contributing to the Project," Journal of software, 7(1), 212-219. 
7. Bendriss, S. and Benabdelhafid, A. (2011), "Data and ontological modeling approach to allowing traceability through freight transportation chain," International Journal of Collaborative Enterprise, 2 (2), 184-202.

8. Bergvall-Kareborn, B. B. Mirijamdotter, A. \& Basden, A. (2004), "Basic principles of SSM modeling: an examination of CATWOE from a soft perspective," Systemic Practice and Action Research, 17(2), 20-32.

9. Borg, Erik A. (2009), "The marketing of innovations in high-technology companies: a network approach," European Journal of Marketing, 43 (3/4), 364-370.

10. Borzacchiello, M.T. Torrieri, V. and Nijkamp, P. (2009), "An operational information systems architecture for assessing sustainable transportation planning: principles and design," Evaluation and Program Planning, 32(4), 381-389.

11. Checkland, P. (1981), Systems Thinking, Systems Practice. Chichester, John Wiley \& Sons.

12. Checkland, P. and Scholes, J. (1990a) Soft Systems Methodology in Practice. Chichester: UK: J. Wiley.

13. (1990b) Soft Systems Methodology in Action. Chichester, New York: J. Wiley and Sons LTD.

14. Checkland, P. and Winter, M. (2006) "Process and content: tow ways of using SSM," Journal of the Operational Research Society, 57(12), 1435-1441.

15. Checkland, P. (1992), "From framework through experience to learning: the essential nature of action research," In: Second World Congress on Action Learning, C.S. Bruce, and A.L. Russell (Eds.), ALARPM Ass Inc, University of Queensland, Brisbane, Australia, 14-17.

16. Delbridge, Rachel and Fisher, Shelagh (...), "The use of soft systems methodology (SSM) in the management of library and information services: a review", Department of Information and Communications, Manchester Metropolitan University, Manchester, UK.

17. Delbridge, R. (2008), "An illustrative application of soft systems methodology (SSM) in a library and information service context: process and outcome," Library Management, 29(6), 538-555.

18. Fava Neves, Marcos (2007), "Strategic marketing plans and collaborative networks," Marketing Intelligence \& Planning, 25(2), 175-192.

19. Ferrari, F.M. Fares, C.B. and Martinelli, D.P. (2002), "The systemic approach of SSM: the case of a Brazilian company," Systemic Practice and Action Research, 15(1), 51-66.
20. Horan, P. (2000), "Using rich pictures in information systems teaching," Paper presented at 1st International Conference on Systems Thinking in Management, 8-10 November, Geelong, Australia.

21. Khakbaz, M.H. and Ghapanchi, A.H. and Tavana, M. (2010). "A multi-criteria decision model for supplier selection in portfolios with interactions," International Services and Operations Management, 7(3), 351-377.

22. Kayaga, S. (2008), "Soft systems methodology for performance measurement in the Uganda watersector," Water Policy, 10(3), 273-284.

23. Klerk, S. de and Kroon, J. (2008), "Business networking relationships for business success," S.Afr.J.Bus, Manage. 39(2) 25.

24. Lindgreen, A. and Antioco, M. (2005), "Customer relationship management: the case of a European bank," Marketing Intelligence \& Planning, 23(2), 136-154.

25. Merati, E. and Zarei, B. and Ghapanchi, A. (2010). "Project Process Re-engineering (PPR): A BPR Method for Projects,"International Journal of Information Systems and Change Management, 4(4), 299 - 313.

26. Mingers, J. Liu, W. and Meng, W. (2009), “Using SSM to structure the identification of inputs and outputs in DEA," Journal of the Operational Research Society.

27. Nagi, E.W.T. To, C.K.M. Ching, V.S.M. Chan, L.K. Lee, M.C.M. Choi, Y.S. and Chai, P.Y.F. (2012), "Development of the conceptual model of energy and utility management in textile processing: a soft systems approach," International Journal of Production Economics, 135(2), 607-617.

28. Nidumolu, U.B. Bie, C. Keulen, H. Skidmore, A.K. and Harmsen, K. (2006), "Review of a land use planning programme through the soft systems methodology," Land Use Policy, 26(2), 187-203.

29. Pesl, J. and Hrebicek, J. (2003), "Soft systems methodology applied to environmental modeling," Environmental Informatics Archives, 1(1), 261-266.

30. Platt, A. and Warwick, S. (1995), "Review of soft systems methodology," Industrial Management \&Data Systems, 95(4), 19-21.

31. Por, J. (2008), "The use of soft system methodology (SSM) in a serviced-focused study on the personal tutor’s role," Nurse Education in Practice, 8(1), 335342.

32. Saad, N.H.M. Alias, R.A and Abdul Rahman, A. (2006), "Using soft systems methodology (SSM) in formulating knowledge management systems (KMS) strategy for Malaysian Public Institutions of 
Higher Education (PIHE)", Paper presented at the 5th International Conference, ICT and Higher Education, Waseda University, 26-29 June 2006, Tokyo, Japan.

33. Sørensen, C.G. Fountas, S., Nash, E. Pesonen, L. Bochtis, D. Pederson, S.M. Basso, B. and Blackmore, S.B. (2010), "Conceptual model of a future farm management information system," Computers and Electronics in Agriculture, 72(1), 37-47.

34. Stowell, F. (2009), "Soft systems and research," Kybernetes, 38(6), 879-896.

35. Swaminathan, Vanitha \& Moorman, Christine (2009), "Marketing Alliances, Firm Networks, and Firm Value Creation," Journal of Marketing, 73 (September), 52-69.

36. Tajino, A. James, R. and Kijima, K. (2005), "Beyond needs analysis: soft systems methodology for meaningful collaboration in EAP course design," Journal of English for Academic Purposes, 4(1), 2743.

37. Trequattrini, Raffaele, Giuseppe Russo, Lombardi, Rosa (2012), "Defining Business Network," International Journal of Business Research and Management (IJBRM), 3 (1).

38. Warwick, J. (2008), "A case study using soft systems methodology in the evolution of a mathematics module," The Montana Mathematics Enthusiast, 15(2/3), 269-290.

39. Williams, B. (2005), "Soft systems methodology," (accessed May 10, 2010), [available at http://www.google.com/url?sa=t\&rct=j\&q=Williams $\% 2 \mathrm{C}+\mathrm{B} . \% 2 \mathrm{C}+(2005) .+\% \mathrm{E} 2 \% 80 \% 9 \mathrm{CSoft}+$ Systems +Methodology\%E2\%80\%9D\&source=web\&cd=1\& ved=0CGEQFjAA\&url=http\%3A\%2F\%2Fwww.ka piti.co.nz\%2Fbobwill\%2Fssm.pdf\&ei=kP2rT6KFD 8TF0QWA0NiGBA\&usg=AFQjCNG5HZfISNs1k8 qHoxiyYdD7Cog4w].

40. Wilson, B. and Haperen, K.V. (2009), "Improving regional policing: a review of protective services. Undertaking an audit of a method of analysis using soft systems methodology," International Journal of Police Science and Management, 12 (2), 206-219.

41. Wolfson, O. Sistla, A.P. and Xo, B. (2012), "The TranQuyl language for data management in intelligent transportation," Transportation Research Part C: Emerging Technologies, 23(August), 3-13. 